\title{
A PROPÓSITO DE SEVILHA E O ATLÂNTICO* NO SÉCULO XVI E MEADOS DO SÉCULO XVII.
}

Depois que Fernand Paul Braudel publicou o seu admirável: "La Mediterranée au temps de Philippe II", inaugurando a via dos estudos dos mares do ponto de vista da história da economia, seria. natural que se lançassem pesquisadores da têmpera dos Chaunu (*) na busca do Atlântico espanhol, no período complementar. Apenas: temos em mãos os dois primeiros exemplares duma série monumental de oito volumes e já estamos prelibando o prazer da leitura dos restantes, bem como antevemos o despertar do interêsse pelo estudo do Atlântico português nessa mesma fase que animará, por certo, algum historiador dessa escola a ampliar os quadros dos conhecimentos de uma época apaixonante sob diversos: prismas.

A obra dos Chaunu cuja envergadura medimos pelos dois primeiros tomos, representa uma vitória do espírito de grupo que, sob a égide do Centre de Recherches Historiques, orientado por Lucien Febvre e Fernand P. Braudel, permitiu a estruturação dêssemanancial magnífico de conhecimentos que a pertinácia, a inteligência e o trabalho dos Chaunu levou a bom têrmo.

Huguette e Pierre Chaunu percorreram uma estrada já palmilhada por outros, com um espírito de observação e síntese inusitados. Suas conclusões, baseadas em dados estatísticos rigorosos, sôbre o comércio espanhol com a América no primeiro século e. meio da conquista, superaram de muito as observações parciais. de Haring que durante tanto tempo constituiram a fonte mais segura para o estudo daquele período.

Desde a introdụção desenvolvem os abalisados autores uma análise profunda da época que estudam em que, após a determi-. nação das razões da tese que defendem, submetem a uma crítica. construtiva tôda a bibliografia fundamental para o estudo econômico da época dos Habsburgos.

(*). - Chaunu, Huguette et Pierre - Seville et 1'Atlantque (1504-1650) - Tomo I - Coleção: Ports-Routes-Trafics. Librairie Arnłand Colin - Paris, 1955. 
Digna de nota é, sem dúvida, a apreciação do valor das obras de Encinas e Veitia y Linage que, com a Recopilacion de las Leyps de las Indias, admiráveis fontes jurídicas mas criadoras de uma ilusão aos especialistas em história que as citam freqüentemente sem investigarem mais longe.

Apontando deficiências de obras fundamentais que criaram uma "description stéréotypée" como a de Scelle relativa ao estudo do comércio negreiro ou a de Haring sôbre o comércio no tempo dos Habsburgos, mostram os autores como uma caudal de do cumentos que repousam nos arquivos podem modificar conceitos clássicos e fundamentais para atingir os resultados de uma história "chifrée, evolutive, dynamique, sciemment, volontairrement quantitative et par surcroit aussi rattachée que possible au contexte de la vie générale du monde qui l'explique de bout en bout, la suit, la soutient ou la contrarie" (pág. 19).

Com êste espírito compreende-se como os Autores praticam o culto da estatística, recusando deliberadamente tudo o que não fôr rigorosamente mensurável (pág. 20). Daí a massa considerável de documentos apresentados no volume II, o primeiro da série estatística, em que se pode apreciar o movimento de navios de 1504 a 1560 , que apesar da "extrema fraqueza da massa documental", cêrca de 600 alentadas páginas, traduzem a partida e a chegada das embarcações ligadas ao tráfico espanhol com as Indias. Os quadros estatísticos organizados pelos Autores, fartamente ilustrados com notas de rodapé de expressiva interpretação histórica, obedecem à determinação do nome do navio, seu mestre e proprietário, natureza, tonelagem, equipamento, idade e direção.

Sòmente quem dispôs de elementos estatísticos tão seguros pode, com autoridade, afirmar, já em notas iniciais, que a xenofobia assinalada em 1505 é tão velha como o papel desempenhado pelos estrangeiros na Carreira das Indias durante todo o período, (Tomo II, pág. 10-nota), tese edmirável que já nos havia seduzido, por excelência, no estudo de uma época mais sensível à sua eclosão como o fôra a da Unificação Peninsular.

A julgar por estas notas preliminares de um primeiro volume que a modéstia dos Chaunu taxou de pobre, podemos, inferir não sòmente a riqueza dos seguintes como a profundidade dos estudos que conduzem à apreciação de certos fenômenos característicos da política comercial espanhola: a luta contra os ataques estrangeiros, a origem e a evolução dos embargos das naus de comércio (vol. II, pág. 157, nota), a fixação do itinerário da carreira cujos rumos se fixam a partir de 1526 (vol. II-pág. 166, nota), as brechas abertas no exclusivismo comercial espanhol pelas arribadas das naus 
em retôrno das Indias a Portugal por volta de 1533 (vol. II-pág: 231, nota), o nascimento da política de embargo dos bens chegados da América a partir de 1535 e sua substituição por títulos de divida pública, os famosos "juros", de rápida depreciação que apenas por esta via compulsória tinham circulação (vol. II-pág. 256). Vinte anos mais tarde, a continuidade da política de embargo dos metais preciosos estimulará a fraude, principalmente as arribədas maliciosas a Portugal, onde os capitais dos particulares estavam a coberto da cobiça real (vol. II- pág. 525, nota); em fins de 1558 a persistência desta política de embargo levará a Casa de la Contratación a tomar o partido dos mercadores, defendendo-lhes os interêsses ao mesmo tempo que visa opor diques à evasão da prata para o estrangeiro (vol. II-pág. 570, nota).

Como fêcho final às judiciosas notas: do volume II sôbre êste tema os Chaunu assinalam o advento a 29 de fevereiro de $1560 \mathrm{da}$ política do "indulto", arma inútil com que a Espanha procurará, na sucessão das décadas seguintes, impedir a evasão dos metais e de mercadorias, visando o perdão àquêles que num curto prazo - 4 meses - restituíssem ao Reino os valores sonegados (vol. II-pág. 597 , nota).

A autoridade de investigadores idôneos não lhes permite, todavia, enveredar pelo campo das afirmações arrojadas. Assim é que diante do registro em 1540 do navio São Pedro cujo capitão, Gil Diaz, tem seguido a seu nome a especificação de "português", bem como a singularidade de ser uma embarcação sem registro deida, não se abalançam os autores a construção de uma teoria definitiva mas sugerem uma tímida hipótese, aventando a idéia de que seja nau de negreiro ou indagando, cautelosamente, se "bien ne doit-on penser que les règles que excluent les étrangers du commerce d'Amerique ont été moins strictement appliquées que des historiens trop uniquement attentifs à la lettre des lois, l'avaient pensé? (vol. II-pág. 321, nota).

Percorrendo as notas do volume II de "Séville et l'Atlantique" não sòmente ganharemos a idéia da política naval espanhola que se cristaliza em 1543, como já bem o observara Carande em seu magnífico estudo - Carlos $V$ y sus banqueros - como podremos perceber até que ponto a pirataria francesa que parece atingir o auge em 1553 (vol. II-pág. 498, nota), influi nos rumos dessa orientação pela continuidade de uma luta que domina todo $o$. campo de investigação dêsse período (1504-1560).

Apenas a investigação paciente e frutífera dos Chaunu permitiria o lançamento da tese de que, em 1550, se processa a "revolução da tonelagem", dados os novos índices que apresentam os na- 
vios empregados na carreira das fndias quando, graças ao invento de $D$. Álvaro de Bazan, os velhos navios de 150 a 200 vão, em má dia, triplicar a sua tonelagem (vol. II-pág. 450, nota). Pouco tempo depois (1554) ao sistema das pequenas frotas freqüentes: sucederá o das grandes frotas espaçadas (vol. II-pág. 508, nota).

Chegamos assim à importante fase do contrabando português, comprovado pelas inúmeras queixas da Contratação ao Conselho das Indias que vão determinar uma série de cédulas reais, severas na repressão do tráfico ilegal. Como o comércio de escravos negros se faz com navios que, demandando aos centros fornecedores, escapam ao contrôle das frotas, transformam-se em agentes do contrabando, já fortemente estimulado pelos portuguêses que, do Algarve, vão às Indias, pelas Canárias, determinando o êxodo da prata para Portugal e Canárias contra o que se volta o decreto real de setembro de 1558, um libelo contra os portuguêses (vol. II-pág. 567, nota) que a conjuntura política transformara em aliados na defesa da Península: terrível dilema espanhol sintetizado admiràvelmente por Chaunu nesta frase tão rica de significado: "Ainsi Seville et l'Espagne se trouvent prises entre le désir d'une collaboration et les dangers que répresente pour l'économie de Séville, le voisinage portugais" (vol. II, pág. 568, nota).

O conceito de uma ciência do mensurável para a elaboração de uma história econômica, dinâmica e quantitativa, levou os autores de "Séville et l'Atlantique" à tarefa árdua de se transformarem em estatistas de um período em que as medidas "autant plus precieuses qu'elles sont plus rares, nous sont parvenues en mauvais état" (vol. I-pág. 7).

O campo, ainda que complexo, era admirável principalmente tendo por objetivo o tráfico sevilhano, excepcional pelas suas características diversas dos demais, concentrado em um órgão específico - a Casa de la Conitratación de las Indias - num centro unificador, por excelência, - Sevilha - e num arquivo centralizado - o Archivo General de Indias - onde um único problema se impõe ao pesquisador diante da massa absorvente de documentos (mais de 30.000 carpetas): a seleção de documentos. Aos Chaunu preocupou, precipuamente, a consulta aos livros de registro, os papéis de conta e a correspondência. Todo o primeiro volume de sua obra indispensável aos estudiosos da economia européia da época, gira em tôrno da análise dêstes três elementos essenciais para a interpretação quantitativa e dinâmica da história econômica da Espanha nesse período (1504-1650).

Valeram-se, primeiramente, do Livro de Registros, fonte indispensável para a elaboração da lista exaustiva de navios à saída 
e à entrada de Sevilha, em contacto com a América. Documentação malbaratada por Haring e outros autores, nem sempre contínua e completa, mas de valor incalculável para o conhecimento da época.

No estudo criterioso e objetivo dessa fonte documental chegam os autores a uma interrogação: é o Livro de Registros completo? Refutam, a priori, o juízo severo de Haring que descria da validade dos registros pela falta de meios de verificação de sua idoneidade. E', sem dúvida, revelador do profundo conhecimento dêsse importante manancial por parte dos Autores o estudo que realizam das diversas fases da evolução dos registros das naus. Não se limitaram os Autores para a verificação da correção dos apontamentos do Livro de Registros à simples apuração de elementos internos. Foram além. Valendo-se de elementos externos como do "Catalogo de los fondos americanos del Archivo de Protocolos de Sevilla" submeteram à verificação os dados dos navios ali citados com os constantes de seu fundo documental com resultados sempre positivos que robustecem sua fé nos preciosos registros.

E serão êstes registros cuja massa documental poderemos apreciar através de quadros classificadores dos fundos existentes no Archivo General de Indias e apresentados pelos Autores nas páginas 85 e 87 , que irão constituir o valioso acervo para a apreciação da época estudada em função de sua importância econômica.

Difícil tarefa realizam os abalizados economistas franceses quando se propõem a mostrar o valor relativo de certos elementos estatísticos como o registro de mercadorias, suspeitos pelo império da fraude que examinam em diferentes aspectos para chegarem à conclusão: "Système grossier, le registre de marchandises a une valeur absolue mais limitée. Système quantitatif il n'est jamais un système qualitatif; quantitativement, il est absolument valable, qualitativement il vaut peu et reste eloigné de la realité" (vol. I, pág. 124).

Seria preciso, pois, que o economista, obrigado a raciocinar com dados mais completos $e$ positivos, procurasse um elemento marginal "um têrmo seguro de referência", que suprisse as falhas e deficiências dos cálculos baseados em elementos tão aleatórios. "Les pièces d'identité du navire, - afirmam os cultos economistas dans la mesure ou elles livrent directement ou indirectement le tonnage, donnent le chiffre sur. Cette base degagée, on peut esperer obtenir une serie chiffrée continue et suffisament objetive pour permettre raisonnements et calculs indispensables à toute analyse économique" (vol. I, pág. 124). Daí a importância que emprestam ao navio para conhecer-lhe a tonelagem "cet autre ele- 
ment quantitatif le moins recusable, le plus degagé de toute subjectivité fiscale..." (vol. I, pág. 125).

Ainda neste setor evidenciam os elaboradores de "Séville et L'Atlantique", na análise do fator tonelagem, o mesmo escrúpulo na apuração da fidelidiade dos dados de registro através de estudos comparativos de diferentes registros de um mesmo navio para chegarem à conclusão de que em $98 \%$ dos casos as informações coincidem (vol. I, pág. 129).

O acurado estudo dos Chaunu para caracterizarem a tonelada em suas variações, no tempo e no espaço, encerra-se com a conclusão de que a tonelagem é "la meilleure approche quantitative possible de la vie economique de l'espace Atlantique hispano-americain". E' o que estará reservado à análise dos leitores $\mathrm{em}$ volumes que ainda não sairam à luz, mas que os Autores reputam como uma série documental de inestimável valor (vol. I, pág. 146).

Não basta, todavia, a tonelagem, continuam os Autores, para a construção estatística, contínua, conducente a uma análise econômica ponderável. Há outros valores que a completam. Assim os papéis de conta que oferecem a possibilidade de reconstituição, pelo menos parcialmente, do movimento das mercadorias e o do valor (vol. I, pág. 167). Finalmente o estudo da correspondência da Casa de la Contratación, submetida à mesma interpretação em série, pode contribuir decisivamente para o conhecimento da história dos preços, dos tráficos e das distâncias.

Todos êstes elementos são rigorosamente filtrados pelos Chaunu que dissecam a instituição da "averia" em fontes documentais e bibliográficas, desde a sua origem até o momento em que ela deixa de ser um impôsto "ad valorem", minguando, portanto, o interêsse para a interpretação do volume do comércio.

Completa êste estudo o que os Autores chamaram "Séries anexas aos papéis da averia", papéis da Armada, contas dos pagadores de armadas, e outras que se distribuem por centenas de carpetas, oferecendo base para estudos complementares que não apenas interessam ao campo específico das investigações dos Autores como permitem, a seu juízo, outras pesquisas de não menor transcendência para o conhecimento da história hispano-americana. Curiosa observação aduzem ainda os Chaunu ao tratarem da correspondência da $\mathrm{Ca}$ sa de la Contratación que, ainda que não apresente o caráter de densidade e continuidade, "permet d'établir la jurisprudence de la construction estatistique, sans laquelle les anciennes mesures eussent été difficilement utilisables et interpretables (vol. I, pág. 253)... Et l'on arrive à cet apparent paradoxe que ce document non statistique, à une étude de frequence: une série de la correspondance de 
la Casa de la Contratacion constitue donc le document par excellence, en vue de la constitution d'une psychologie collective de la conjuncture" (vol. I, pág. 253).

Foi nessa fonte que os traçadores dessa importante contribuição para o conhecimento do Atlântico espanhol encontraram elemento indispensável para as notas de rodapé que dão vida à monotona sequiência de dados estatísticos que ilustram o II volume de sua monumental obra.

$$
* *
$$

Quem quer que se disponha a conhecer os fundamentos da técnica da moderna escola economista francesa representada pelo grupo a que hoje se incorporam os Chaunu como legítimos representantes da renovação da cultura histórico-econômica, encontrará, por certo, na 3a. parte de "Séville et l'Atlantique", sob o título de "La construction statistique", a sintese do método quantitativo que lhes permitiu enfrentar a árdua tarefa de reconstituição da história do Atlântico espanhol por cêrća de um século e meio.

Favorecidos por fatôres excepcionais para a pesquisa em Espanha, - primazia do tráfico, administração sem par, monopólio centralizador e rara conservação dos arquivos espanhóis - puderam abalançar-se à tarefa ingente: passar do discontínuo ao contínuo, adaptar a concepção do século XVI à do século XX. Assim se explica como recorrem os Autores a tão numerosas fontes para o traçamento dos quadros estatísticos, de acôrdo com a exigência do século em que vivemos, quando essa preocupação não se enquadrava na mentalidade do homem do século da conquista de tão apoucada capacidade para os registros que pudessem favorecer o traçamento das modernas tabelas interpretativas dos valores quantitativos.

O ponto de partida para a larga emprêsa estatística concentrou-se no movimento das navios que partiam do conjunto monopolístico andaluz-canarino para as Índias, objeto dos volumes II a $\mathrm{V}$. Para que se tenha idéia do volume da análise do tráfico comercial empreendida pelos Chaunu, basta que saibamos que 17.761 travessias ocupam a sua atenção no período em estudo (15.000 constantes do Libro de Registros e as restantes computadas em outras fontes).

Milagre de paciência a identificação individual de cada uma dessas unidades para reconstituir-lhes o nome, o mestre, a natureza da embarcação, o destino, a espécie da carga, o proprietário, a idade do navio, a equipagem e, finalmente, o elemento econômicamente mais importante - a tonelagem. 
Largo estudo realizam os Autores dêsse fator decisivo para o estabelecimento das estatísticas. Detêm-se, particularmente, na análise de certos aspectos do problema como, por exemplo, dos navios adstritos ao transporte do mercúrio e dos negros, especialmente dêstes, cuja tonelagem pode ser aferida por diversos documentos.

Interessantes são as observações dos doutos pesquisadores sôbre êste nebuloso comércio de negros, exercido sem nenhum contrôle espanhol nas fontes de aprovisionamento de Cabo Verde a Angola. O contrabando tende a exercer-se à margem de uma história econômica, dinâmica e quantitativa, ainda que as leis espanholas houvessem estabelecido a eqüação de 1 escravo por 1 tonelada (Célula real de 4-VIII-1561). Mas o tráfego de escravos negros foge aos contrôles por uma série de fatôres (navegação fora de frotas, partida direta de Âfrica, etc.). Entretanto, crêem assim os autores de Séville et l'Atlantique, baseados em Watte Stewart (Chinese Bondage in Peru - Duke University) Press, 1951), "le rapport I homme/1 tonneau était le rapport le plus courant, celui qui pratiquement constituait um mur qu'on avait ni possibilité tecnique, ni intérêt... à crever (vol. I, pág. 312).

Um título especial do tomo primeiro da obra dos Chaunu ocupou particularmente a nossa atenção - o dedicado aos Registros de navires negriers - pela singularidade de constituir um dos aspectos de nossa tese doutoral a sair à luz em princípios de 1957 .

Ocupando-se do assunto os autores de Séville et l'Atlantique fixam inicialmente a importância dêstes registros que, a seu ver, não possuem a constância e a uniformidade dos demais. Concorre para isso o fato dos navios desta espécie poderem sair de um pôrto não pertencente ao complexo portuário andaluz-canarino como Lisboa.

Ora, as partidas de Lisboa, fora das vistas da Casa de la Contratación, "il n'était sans doute pas question de visite" (vol. I, pág. 156). $O$ assunto mereceria um certo alargamento que permitisse fixar melhor o mecanismo das partidas de Lisboa, submetidas à fiscalização do representante espanhol que, pelo menos teòricamente, deveria impor aos negreiros em Portugal condições semelhantes às vigentes em Espanha.

O quadro das partidas de Lisboa de 1594 a 1640, segundo o Libro de Registros, publicado às págs. 162-163 do Tomo primeiro de Séville et l'Atlantique, oferece margem a algumas considerações interessantes a que nos propomos no sentido de oferecer aos ilustres economistas franceses a oportunidade para novas considerações do problema em face de nossa contribuição. 
Diante de algumas contradições entre os dados consignados pelos tratadistas franceses extraídos do Libro de Registros durante o período da Unificação Peninsular, e os que obtivemos nos registros especiais da Casa de la Contratación (Archivo General de Las Indias - Contratación - Legajos n. 5763 , Lo. 2, e, 5766, Lo. 1,2 e 3), sentimo-nos tentado à confrontação de ambos os dados.

Comecemos pelos totais dos navios consignados pelos Chaunu e os que registramos nas fontes citadas, a partir de 1604:

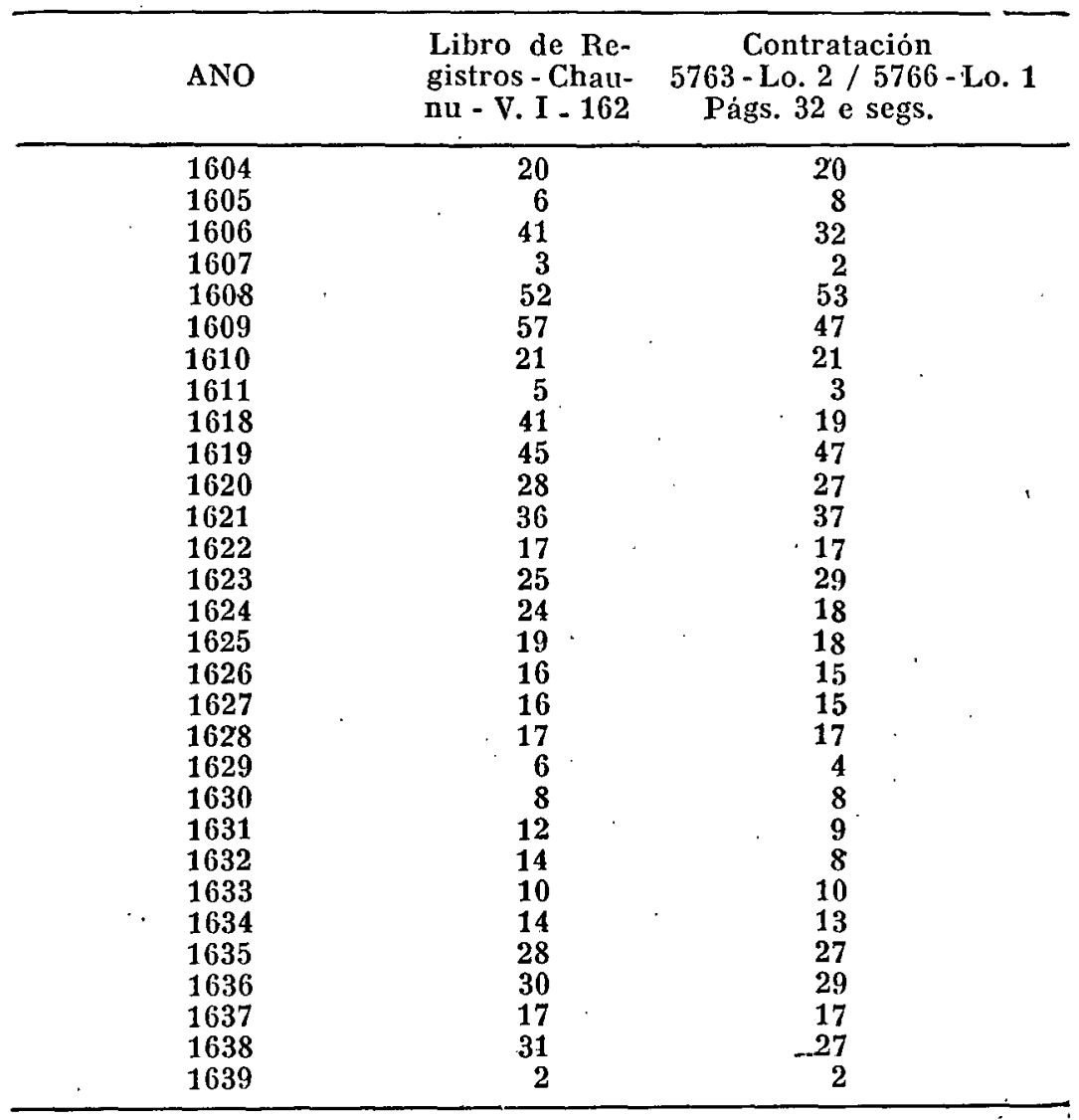

Como se vê, quase desaparecem as discrepâncias, a partir de 1619, entre as duas fontes: o Libro de Registros e os assentamentos da Contratación. Aguardamos, portanto, com vivo interêsse a publicação do tomo da notável obra dos Chaunu relativa a êste período para um estudo mais profundo do assunto. 
Não menos inquietantes são as divergências assinaladas entre as duas fontes do mesmo Arquivo com respeito às partidas de navios negreiros do pôrto de Lisboa. Apresentamos, em seguida, ambos os dados, os apontados pelos Chaunu, segundo o Libro de Registros e os obtidos por nós, na Contratación:

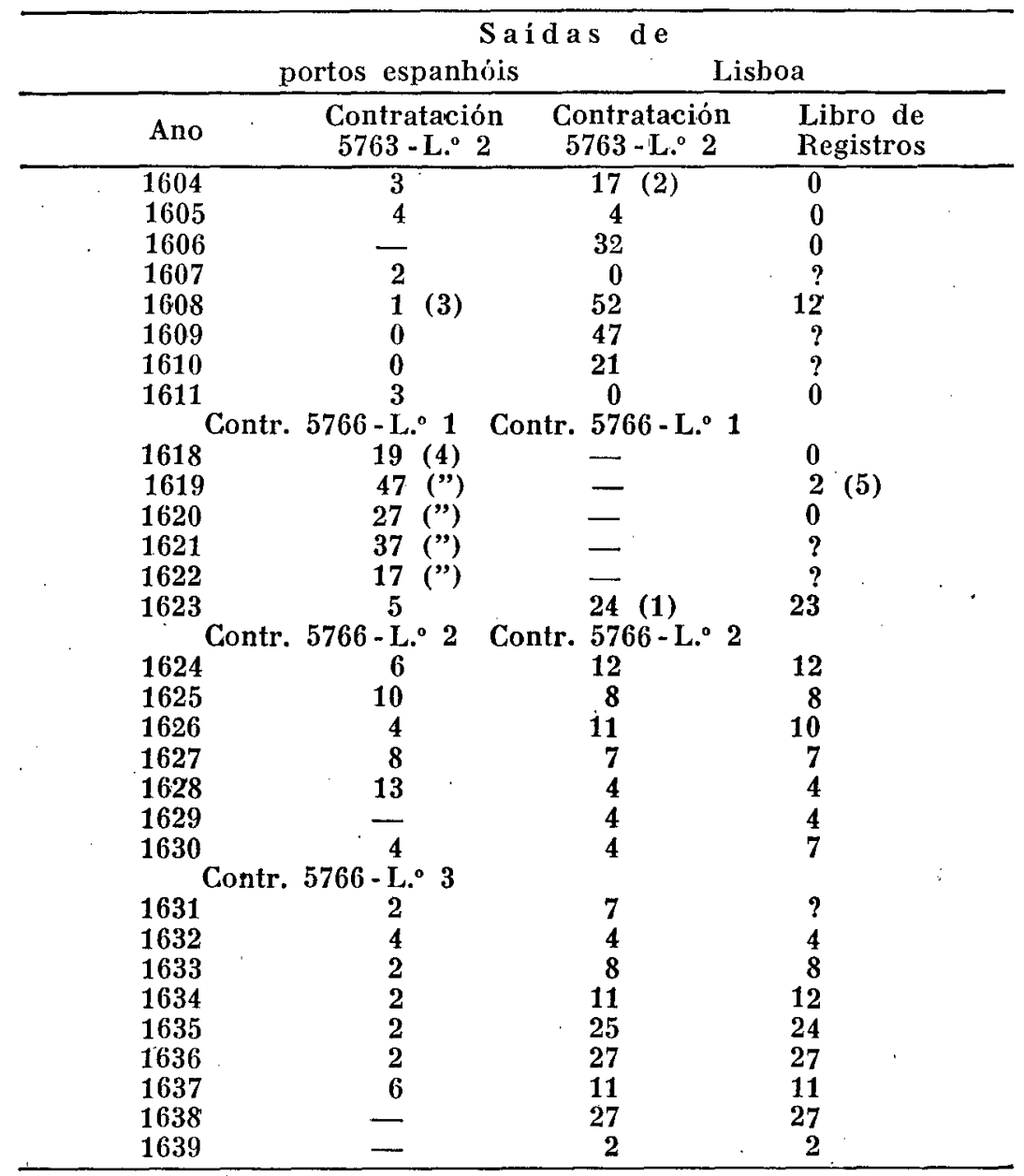

(1). - Proibição levantada pela cédula real de $13-\mathbf{X}-1622$

(2). - 1 saindo de La Palma (N. S. de la Esperança - Luis Sanchez para La Havana com 70 escravos).

(3). - N. S. del Rosario, mestre Francisco Perez (?) para S. Juan de Ulloa com 150 escravos

(4). - Tôdas as licenças são para S. Lucar ou Cadiz.

(5). - Não parece possível na época, em fase da intransigência de Filipe IIL em concentrar o comércio de escravos negros em Sevilha, pudessem êstes dois navios 
A análise dos dados expostos anteriormente comprova a verdade fundamental já consolidada pelo agudo espírito de observação dos Chaunu - a precariedade da fonte única para verificação das leis histórico-econômicas. Os dados que faltam no Libro de Registros para a determinação da importância do pôrto de Lisboa no período da Unificação Peninsular, podem ser obtidos por outra fonte complementar = Contratación - Asientos de Esclavos.

Verificamos, assim, que, à hegemonia do pôrto lisboeta na primeira década do século XVII, sucede a fase do ostracismo ditada pela política anti-lusitana do terceiro dos Habsburgos que morre inabalável em seu ideal, de que se afasta o seu sucessor, Filipe IV de Espanha, que devolve à Lisboa o seu prestígio, hesitante por volta do fim do primeiro quartel do século XVII, mas consolidado novamente no decênio seguinte (1631-1640) quando a Restauração Portuguêsa veio impor novos rumos às diretrizes comerciais dos dinastas espanhóis.

ROZENDO SAMPAIO GARCIA

Assistente da Cadeira de História Americana da Faculdade de Filosofia, Ciências e Letras da Universidade de São Paulo.

romper esta barreira. Aliás, os apontamentos da Contratación não acusam êstes navios com permissäo para Lisboa. A mudança da orientação espanhola no tocante ao tráfico negreiro sommente se processaria a partir de 13-X-1622 quando o novo soberano, atendendo às representaçōes de $D$. Fernando Alvia de Castro e da Casa de la Contratación, em face do desinterêsse espanhol' pelo comércio negreiro, resolve expedir cédula real restituindo a Lisboa o privilégio da expediçāo de navios negreiros como anteriormente (A. G. I. - Cedulario 2767 Lo. I - pág. 129). 